\title{
Numerical and experimental study for AM50 magnesium alloy under dynamic loads
}

\author{
Iulian-Ionuț Ailinei ${ }^{1}$, Sergiu-Valentin Galațanu ${ }^{1 *}$, Cosmin Ioan Onea $^{1}$, Liviu Marșavina ${ }^{1}$ \\ ${ }^{1}$ University Politehnica Timisoara, Department Mechanics and Strength of Materials, 1 Mihai \\ Viteazul Blvd., 300222, Timisoara, Romania
}

\begin{abstract}
Magnesium alloys are widely used in automotive (steering wheel frames) and aerospace due to their lightweight, ductility, energy absorp tion and castability properties. Finite Element Analysis and design optimisation have driven the improvement of structural crashworthiness, stiffness, strength, durability, and $\mathrm{NVH}$ (noise vibration, harshness) performance, making it possible to meet both the safety requirements and weight reduction targets. The accuracy of the numerical methods is strongly dependent on the accuracy of the material models and parameters employed. This paper presents the numerical Simulation of the Charpy test for AM50 magnesium alloy. This standardised high-speed impact test method measures the energy absorbed by a standard specimen while breaking under an impact load. Numerical simulations were performed using Ansys LS-Dyna explicit solver combined with a Johnson-Cook material's law. Then a sensitivity study was performed using Ansys optiSLang to identify which of the input variables (JC parameters, test specimen's dimensions) has the most influence on the output variables (contact force and absorbed energy).
\end{abstract}

\section{Introduction}

Magnesiumalloys were first us ed in the mechanical industry in aeros pace construction [1]. Due to their excellent rigidity, ductility, and high strength-to-weight ratios, magnesiumalloys increase their applications in various fields, from automotive to aerospace and biomedical engineering [2] [3] [4]. Likewise, magnesium alloys have been adopted for different structural and non-structural components [2] [5] [6] [7]. The investigations from [8] show that casting and subsequent hot rolling enables the production of magnesium alloy sheets containing grain refining additives. In as -cast conditions, all investigated additives increase the strength values compared to the base alloys. The effects of the solution treatment process and ageing treatments on the microstructure and mechanical properties of the AM50-4\% $(\mathrm{Zn}, \mathrm{Y})$ alloy were investigated by Dai [9].

The inves tigations from [8] show that casting and subsequent hot rolling enables the production of magnesium alloy sheets containing grain refining additives. In as -cast conditions, all investigated additives increase the strength values compared to the basealloys. The effects of the solution treatment process and ageing treatments on the microstructure and mechanical properties of the AM50-4\% (Zn, Y) alloy were investigated by Dai [9]. Both

* Corresponding author: sergiu.galatanu@upt.ro 
quasi-static and dynamic tests were conducted on different specimens die-cast, showing, in general, good ductility and capacity to absorb energy for AM50 Magnesiumalloy [10]. The fatigue behaviour of AM50 was investigated in [11]. Dynamic fracture toughness of AZ61 magnesium alloy was investigated by Daud [12].

A numerical simulation of the behaviour of the magnesium alloy AM50 in tension and torsion was performed by Serban [13]. The advantages of the Johnson-Cook model over the linear elastic/plastic model are that it is easier to calibrate and determines shorter simulation times, but in terms of simulation accuracy, the linear elastic model with is otropic plasticity is optimal.

The purpose of this paper is to validate a numerical model of the Charpy test for AM50 magnes iumalloy, considering the experimental results presented in the first part of the paper.

\section{Experimental Material and Method}

For the mechanical characterisation of the AM50 Magnesiumalloy, specimens type 1 were us ed according to Fig. 1. Type 1 specimens with rectangular sections were used for tests under dynamic loading. The specimens were cast under pressure in the same conditions and technological parameters used to obtain the steering wheels. The experimental investigations are considered to be followed on Charpy impact. For this reas on, the specimens were mechanically machined at the ends, and their shape became a parallelepiped, Fig. 2.

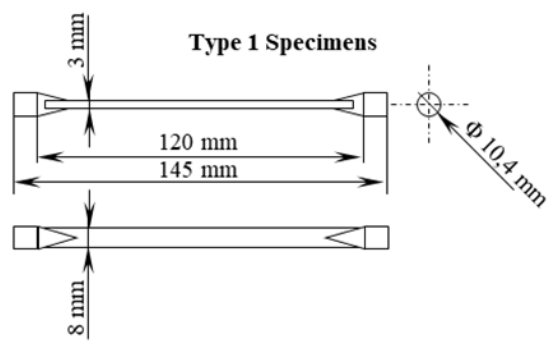

Fig. 1. Type 1 specimen with rectangular section.

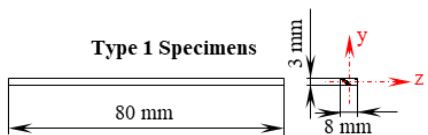

Fig. 2. Specimens after machining

The specimens obtained were tested in two directions as follows:

- In the $\mathrm{z}$-direction (edgewise direction): denoted by $\mathrm{W}$, having $\mathrm{b} \approx 8 \mathrm{~mm}$ and $\mathrm{h} \approx 3$ $\mathrm{mm}$, respectively

- In the $\mathrm{y}$-direction (Flatwise direction): denoted by $\mathrm{L}$, having $\mathrm{b} \approx 3 \mathrm{~mm}$ and $\mathrm{h} \approx 8$ $\mathrm{mm}$, respectively.

The tests were performed with the Charpy hammer of $25 \mathrm{~J}$. The impact velocity was 3.8 $\mathrm{m} / \mathrm{s}$, and the striker was released fromits initial position, an an gle of $150^{\circ}$ with the horizontal plane. The striking hammer capacity is $4 \mathrm{kN}$.

A specimen ready to be tested in the z-direction is presented in Fig. 3. The length of support was adjusted to $40 \mathrm{~mm}$.

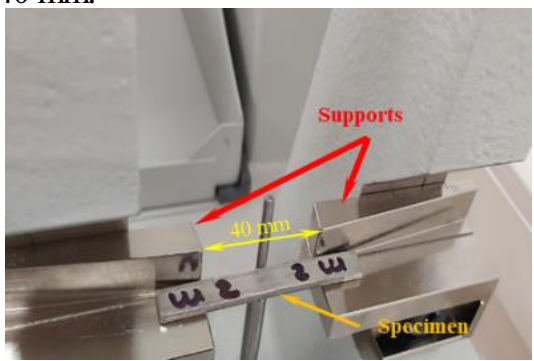

Fig. 3. Placing specimen on supports in order to be test ed. 
A total of 10 Charpy impact tests were performed, five tests for each loading direction. Test specimens cross-section dimensions are shown in Table 1. The minimum and maximum values, respectively their average, are highlighted.

Table 1. Dimensions of the specimens tested in the $\mathrm{z}$ and $\mathrm{y}$ directions.

\begin{tabular}{|c|c|c|c|}
\hline Specimens & $\begin{array}{c}\text { Width } \\
\mathrm{b} \\
{[\mathrm{mm}]}\end{array}$ & $\begin{array}{c}\text { Height } \\
\mathrm{h} \\
{[\mathrm{mm}]}\end{array}$ & $\begin{array}{c}\text { Cross } \\
\text { section } \\
\mathrm{A}_{0}\left[\mathrm{~mm}^{2}\right]\end{array}$ \\
\hline $\mathbf{w 1}$ & 7.95 & 2.95 & $\mathbf{2 3 . 4 5}$ \\
\hline $\mathbf{w 2}$ & 7.86 & 2.96 & 23.26 \\
\hline $\mathbf{w 3}$ & 7.93 & 2.97 & 23.55 \\
\hline $\mathbf{w 4}$ & 7.92 & 2.93 & 23.20 \\
\hline $\mathbf{w 5}$ & 7.75 & $\mathbf{2 . 8 9}$ & $\mathbf{2 2 . 4 0}$ \\
\hline Average & 7.882 & 2.94 & 23.17 \\
\hline
\end{tabular}

\begin{tabular}{|c|c|c|c|}
\hline Specimens & $\begin{array}{c}\text { Width } \\
\mathrm{b} \\
{[\mathrm{mm}]}\end{array}$ & $\begin{array}{c}\text { Height } \\
\mathrm{h} \\
{[\mathrm{mm}]}\end{array}$ & $\begin{array}{c}\text { Cross } \\
\text { section } \\
\mathrm{A}_{0}\left[\mathrm{~mm}^{2}\right]\end{array}$ \\
\hline $\mathbf{L 1}$ & 7.94 & $\mathbf{2 . 9 5}$ & 23.42 \\
\hline L2 & 7.80 & $\mathbf{2 . 9 5}$ & $\mathbf{2 3 . 0 1}$ \\
\hline L3 & 7.96 & 2.98 & 23.72 \\
\hline L4 & 7.90 & 2.98 & 23.54 \\
\hline L5 & 7.90 & $\mathbf{3 . 0 3}$ & $\mathbf{2 3 . 9 4}$ \\
\hline Average & 7.9 & 2.978 & 23.53 \\
\hline
\end{tabular}

\section{Experimental Results and Analysis}

Following the tests performed, CEAST 9050 Pendulum Impact System allows the visualis ation of different graphs that increase the understanding of AM50 magnes iumalloy behaviour under dynamic loads.

Impact Energy - Deflection curve, respectively Impact Force - Deflection curves obtained for the specimens tested in the z-direction are presented in Fig. 4 and Fig.5. Deflection is the displacement of the striker relative to the test specimen supports after impact, starting at first contact between striker and test specimen.

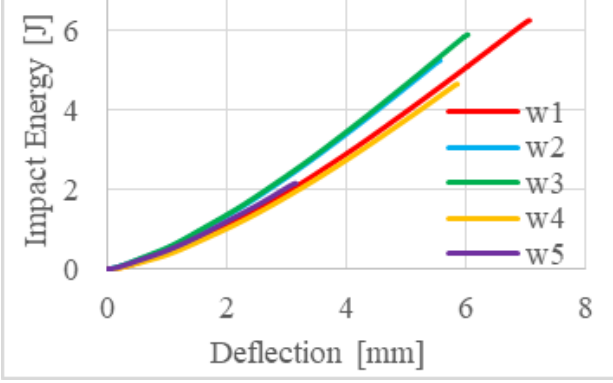

Fig. 4. Deflection - Impact Energy curve for specimens tested in the z-direction

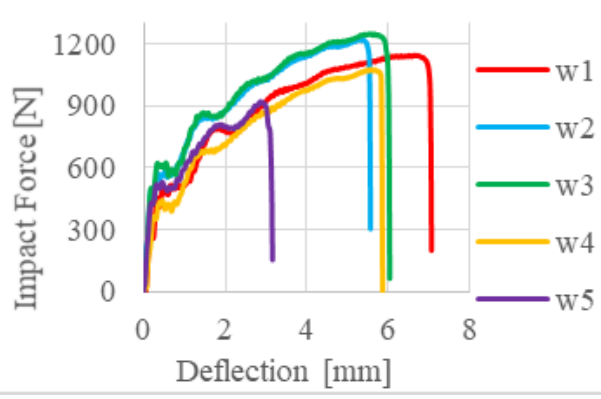

Fig. 5. Deflection - Impact Force curve for specimens tested in the z-direction

As observed in the figures above and table 2, most of the specimens have the same behaviour at impact, except the $\mathrm{w} 5$ specimen. The $\mathrm{w} 5 \mathrm{specimen}$ has a smaller cros s-section, but at the same time, following the analy sis of the breaking area, it could be seen that it has defects inside. If we exclude from analys is these values, it can be observed that the average of the impact energy is $5.49 \mathrm{~J}$, the maximum average of the impact force is $1172 \mathrm{~N}$, and the deflection at the break is $6.12 \mathrm{~mm}$, respectively.

All the specimens have been break following the tests, Fig. 6. 


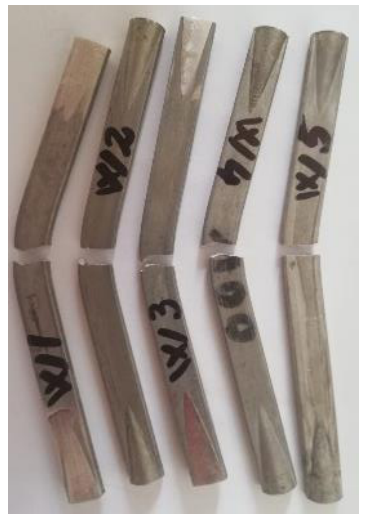

Fig. 6. Specimens tested in the z-direction

\begin{tabular}{|c|c|c|c|}
\hline Specimens & $\begin{array}{c}\text { Impact } \\
\text { Energy } \\
\mathrm{W}[\mathrm{J}]\end{array}$ & $\begin{array}{c}\text { Maximum } \\
\text { Impact Force } \\
\mathrm{F}_{M}[\mathrm{~N}]\end{array}$ & $\begin{array}{c}\text { Deflection } \\
\mathrm{s}[\mathrm{mm}]\end{array}$ \\
\hline $\mathbf{w 1}$ & $\mathbf{6 . 2 4}$ & 1144.53 & 7.06 \\
\hline $\mathbf{w 2}$ & 5.23 & 1222.51 & 5.57 \\
\hline $\mathbf{w 3}$ & 5.88 & $\mathbf{1 2 4 7 . 6 5}$ & 6.03 \\
\hline $\mathbf{w 4}$ & 4.64 & 1076.30 & 5.85 \\
\hline $\mathbf{w 5}$ & $\mathbf{2 . 1 5}$ & $\mathbf{9 1 9 . 8 3}$ & $\mathbf{3 . 1 5}$ \\
\hline Average & $\mathbf{4 . 8 2}$ & $\mathbf{1 1 2 2 . 1 6}$ & $\mathbf{5 . 5 3}$ \\
\hline
\end{tabular}

Table 2. Results obtained for the specimens tested in the z-direction

Impact Energy - Deflection curve obtained for the specimens tested in they-direction are presented in Fig. 7. Only two specimens have been broken following the test (L1 and L3). The average deflection at the break is $20.12 \mathrm{~mm}$, respectively $5.98 \mathrm{~J}$ is the impact energy for these specimens.

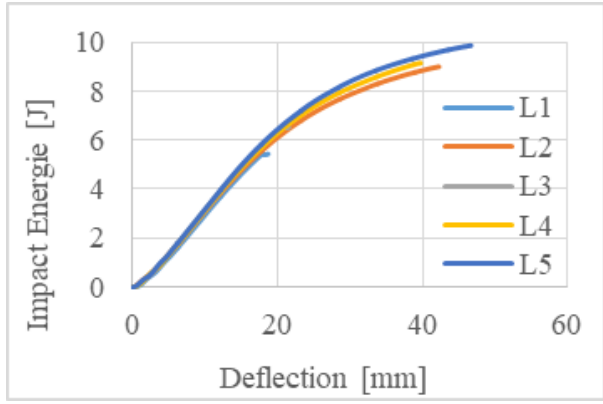

Fig. 7. Deflection - Impact Energy curve for specimens tested in the y-direction

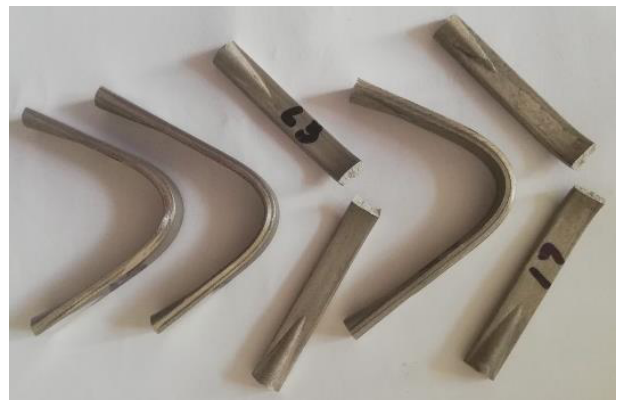

Fig. 8. Specimens tested in the y-direction

The impact velocity reaches the value of $3.8 \mathrm{~m} / \mathrm{s}$ for our study. Current experimental results agree with Galatanu [10], who shows that the values of absorbed energy for $3 \mathrm{~m} / \mathrm{s}$ test velocity reached $5.45 \mathrm{~J}$, respectively for $5 \mathrm{~m} / \mathrm{s}$ test velocity reached $5.82 \mathrm{~J}$.

The results show, in general, good ductility and capacity to absorb energy for AM50 Magnesium alloy.

Furthermore, a validation of a numerical model was achieved considering the experimental results.

\section{Numerical analysis}

\subsection{Finite Element model}

An explicit FEA simulation of the Charpy test was performed using LS-Dyna Solver under Ansys Workbench. The FE model Fig. 9 was built considering the test specimens' entire geometry, but simplified ones for the impact hammer (striker) and supports. The geometry was discretised using first order, full integrated hexahedral elements of $0.5 \mathrm{~mm}$. length, Fig. 10. Striker and supports were defined as rigid bodies, and DOF were blocked, except 
for the $\mathrm{Z}$ trans lation of the striker, to allow applying the initial velocity boundary condition. The numerical Simulation of the Charpy test was based on an impact hammer having a kinetic energy of $25 \mathrm{~J}$, generated by a pendulumweight of $3.46 \mathrm{~kg}$ and an impact velocity of $3.8 \mathrm{~m} / \mathrm{s}$. The striker's density was numerically increased so that multiplied by theimpact velocity, the impact kinetic energy of $25 \mathrm{~J}$ was achieved. Two load cases were computed. In the first one, the test specimens were impacted in edgewise direction Fig. 9a and then flipped with $90^{\circ}$ Fig. $9 \mathrm{~b}$.

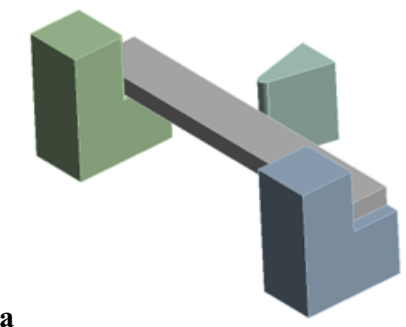

b

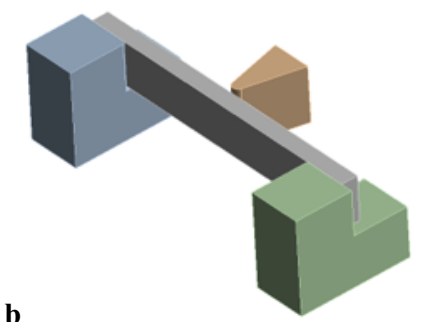

Fig. 9. Numerical simulation Load cases, a - edgewise direction, $b$ - Flatwise direction
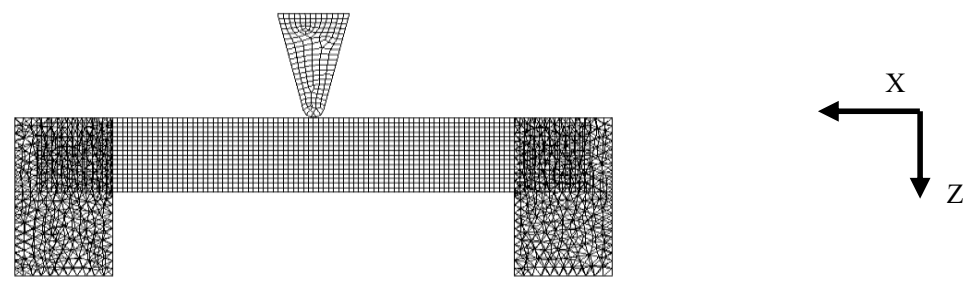

\subsection{Material Model}

One of the most us ed material law in dynamic, highly non-linear simulation is the JohnsonCook $(\mathrm{J}-\mathrm{C})$ strength model[14] coupled with fracture criteria. This isotropic elastoplastic law expresses material stress as a function of strain, strain rate and temperature.

$$
\sigma=\left(a+b \varepsilon_{p}^{n}\right)\left(1+c \operatorname{Ln} \frac{\dot{\varepsilon}}{\dot{\varepsilon_{0}}}\right)\left(1-T^{m}\right)
$$

$\sigma=$ Stress $; \varepsilon_{p}=$ Plastic strain $; a=$ Yield Stress $; b=$ Hardening Modulus ;

$n=$ Hardening Exponent $; c=$ Strain rate Coeficient $; \dot{\varepsilon}=$ Strain rate ;

$\varepsilon_{0}=$ reference strain rate .

Assuming that the material is not temperature nor strain-rate dependent, the J-C parameters can be computed from the uniaxial tensile test, as follows:

$$
a=\sigma_{y} ; \quad n=\frac{\sigma_{u} \varepsilon_{u}}{\sigma_{u}-\sigma_{y}} ; \quad b=\frac{\sigma_{u}}{b \varepsilon_{u}^{(n-1)}}
$$

For the current analysis, J-C parameters were computed based on tensile tes t specimens with similar shape and size [2], shown in Table 3. The true stress-plastic strain is depicted in Fig. 11.

Tabel 3 Johnson-Cook parameters for AM50

\begin{tabular}{|c|c|c|c|}
\hline & $\begin{array}{c}\text { Yield Stress, } \\
\text { a [MPa] }\end{array}$ & $\begin{array}{c}\text { Hardening Modulus, } \\
\text { b [MPa] }\end{array}$ & $\begin{array}{c}\text { Hardening Exponent, } \\
\mathbf{n}\end{array}$ \\
\hline AM 50 & 123 & 215 & 0.1913 \\
\hline
\end{tabular}




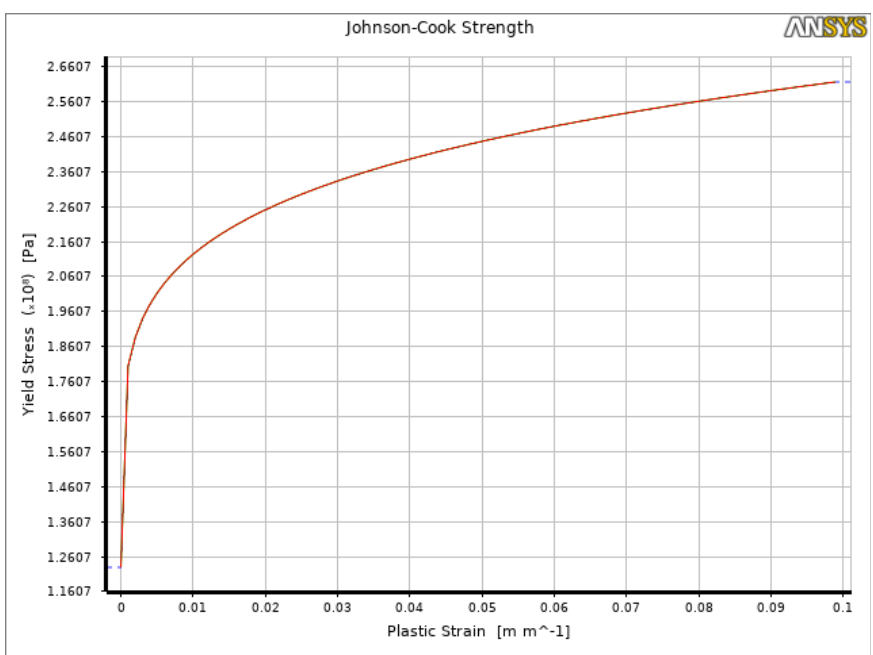

Fig. 11 True Stress versus logarithmic plastic strain of AM 50 magnesium alloy

\section{Comparison with Experimental Results}

\subsection{Numerical analyses results}

Numerical analys es results, performed with nominal geometry dimension $(8 \times 3 \mathrm{~mm})$ and $\mathrm{J}-\mathrm{C}$ parameters described above, are shown in Fig. 12 and 13. One can observe that maximum contact force is overestimated, es pecially at the beginning of the simulation. At the end of the calculation, the velocity drop is also overestimated, suggesting that the numerical model is stiffer than in the physical experiment.

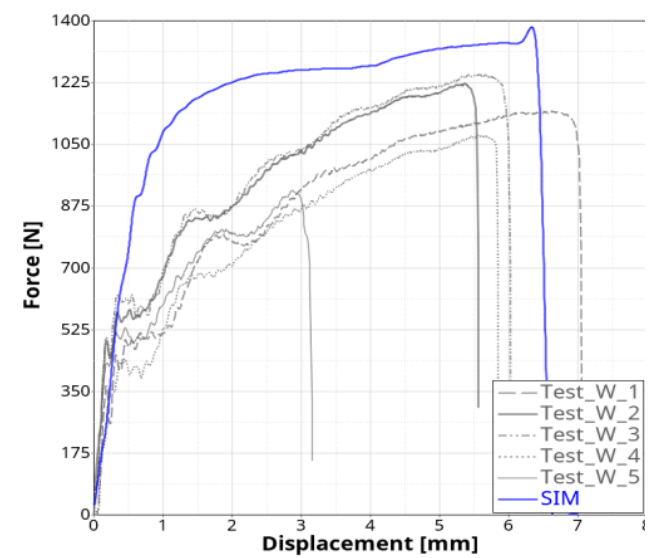

Fig. 12. Force deflection curves, numerical Simulation vs physical tests

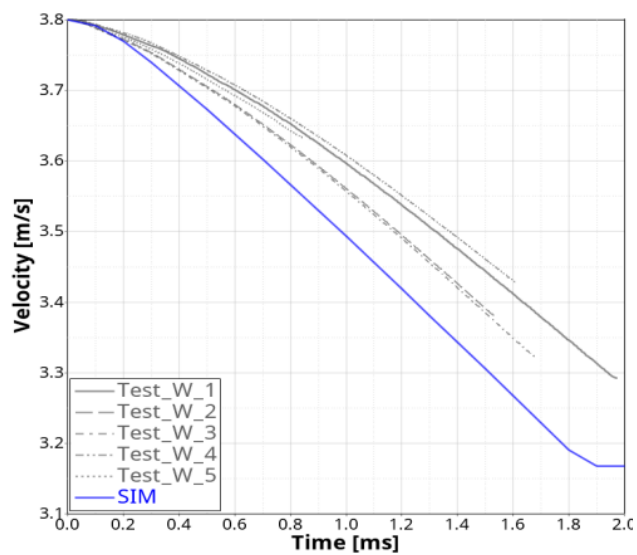

Fig. 13. Velocity vs Time curves, numerical Simulation vs physical tests

\subsection{Sensitivity analyses}

Sensitivity analysis studies how the variations in the input of a model influence the models output. Sensitivity analysis is used during the post-processing of simulation results to analyse 
the contribution of the input variable to the spread of each model response. Using the Metamodel of Optimal Prognosis (MOP) method in OptiSLang [15], the input variables in Table 4 were sys tematically changed by mathematical algorithms until a global optimum was identified.

The objective of this study was to minimise the contact force between the impactor and test probe, from $1400 \mathrm{~N}$ to $1200 \mathrm{~N}$, as seen in experimental tests results (Fig. 5). Based on parameters from table 4, a Design of Experiments (DoE) scheme was automatically generated, with 60 samples. A target of $90 \%$ CoP was defined.

Table 4 Sensitivity analyses input parameters

\begin{tabular}{|l|c|c|c|}
\hline In put parameters & Reference value & \multicolumn{2}{|c|}{ Range } \\
\hline Young's Modulus & 37625 & 33000 & 45000 \\
\hline Initial Yield Stress & 123 & 110 & 135 \\
\hline Maximum Tensile Stress & 280 & 250 & 310 \\
\hline Hardening exponent & 0.1913 & 0.15 & 0.25 \\
\hline Width & 8 & 7.2 & 8.2 \\
\hline Thickness & 3 & 2.89 & 3.2 \\
\hline \multicolumn{3}{|c|}{ Target } \\
\hline Output parameters & 1200 \\
\hline Contact Force &
\end{tabular}

\subsection{Sensitivity results}

As seen in Fig. 14, the sensitivity analyses successfully reached convergence, and the target $\mathrm{CoP}$ of $90 \%$ was targeted. From the same plot, one can conclude that the geometrical dimensions of the test probe have the most influence on the contact force at impact. The Maximum_Tensile_Stress, the failure criteria embedded in the J-Cmaterial model, is the most influentialnon-geometrical parameter that drives the out response. In Fig. 15, one can see the approximate value of the objective (Contact force) regarding both input parameters. The support point, samples of the DoE matrix can be seen and investigated also.

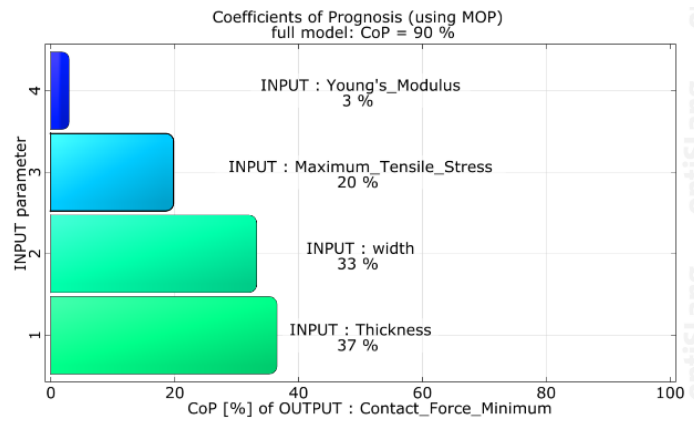

Fig. 14. Coefficient of prognosis

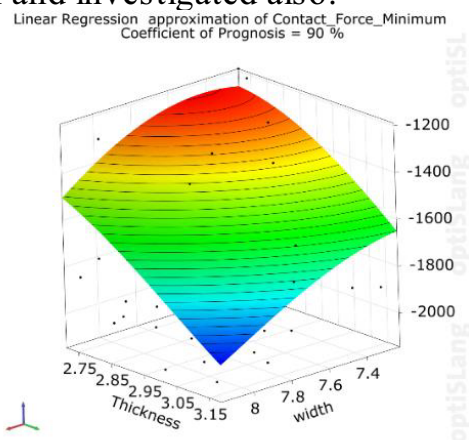

Fig. 15. Response Surface

\section{Conclusions}

The impact behaviour of AM50 magnesium alloy was investigated experimental and numerical. The experimental results for the Charpy impact test of AM50 magnesium alloy agree with those from the literature. Bas ed on the quasi-static tensile tes t, the parameters for Johnson-Cook is otropic elasto-plastic material model were analytically calculated. Explicit 
numerical analyses were conducted to estimate the maximum force during at impact during the Charpy impact test. After the initial FEA results, a sensitive study was performed that proved that geometrical dimensions of the test probe and Maximum Tensile Stress are the most influential on the contact force at impact. Future work will focus on improving FEA correlation by investigating different failure damage limits for tensile and compression loads.

\section{Acknowledgements}

The project leading to this application has received funding from the European Union's Horizon 2020 res earch and innovation program under grant agreement No 857124.

\section{References}

1. S. Annamalai, S. Periyakgoundar, S. Gunas ekaran, Magnesium alloys: a review of applications, Materials and technology 53(6), 881-890, (2019)

2. F. M. Mazzolani, Competing issues for aluminium alloys in structural engineering, Progress in Structural Engineering and Materials 6(4):185 - 196, (October 2014)

3. M. Easton, A. Beer, M. Barnett, C. Davies, G. Dunlop, Y. Durandet, S. Blacket, T. Hilditch, P. Beggs, Magnesium Alloy Applications in Automotive Structures, Sustainable Automotive Technologies, 60(11), (January 2012)

4. D. Dvorsky, J. Kubasek, E. Jablonska, J. Lipov, D. Vojtech, High strength AM50 magnesium alloy as a material for possible stent application in medicine, Materials Technology, 34(14), 838-842 (2019)

5. M.K. Kulekci, Magnesium and its alloys applications in the automotive industry. The International Journal of Advanced Manufacturing Technology, 39(9-10), 851-865, (2008).

6. W. A. Monteiro, Special issues on magnesium alloys. InTech, (2011).

7. R.M. Wang, A. Eliezer, E.M. Gutman, An investigation on the microstructure of an AM50 magnesium alloy, Materials Science and Engineering: A, 355(1-2), 201-207, (2003)

8. K. Neh, M. Ullmann, R. Kawalla, Effect of grain refining additives on microstructure and mechanical properties of the commercial available magnesium alloys AZ31 and AM50, Materials Today: Proceedings 2S S219-S224, (2015)

9. S. Dai, F. Wang, D. Ma, Z. Wang, Z. Liu, P. Mao, Enhanced strengthening by progressive two-step solution and ageing treatment in AM50-4\%(Zn, Y) magnesium alloy, Trans. Nonferrous Met. Soc. China 28 2419-2426, (2018)

10. S.V. Galatanu, M. Scano, D. Pietras, L.D. Pirvulescu, M.C. Porcu, L. Marsavina, Bending behaviour of AM50 Magnesium alloy under static and dynamic loading, Procedia Structural Integrity 26 269-276 (2020)

11. L. Marsavina, F. Iacoviello, L.D. Pirvulescu, V. di Cocco, L. Rusu, Engineering prediction offatigue strength for AM50 magnesium alloys, International Journal of Fatigue 127 10-15 (2019)

12. M. A. M. Daud, N. Z. Nasir, A. Rivai, M.Z. Selamat, Dynamic Fracture Toughness of Magnesium Alloy under Impact Loading Conditions, Procedia Engineering 53639 644, (2013)

13. D. A. Serban, L. Marsavina, L. Rusu, R. Negru, Numerical study of the behaviour of magnesium alloy AM50 in tensile and torsional loadings, Arch Appl Mech 89:911-917, (2019)

14. O. J. Hallquist, LS-Dyna Theoretical Manual, (1998).

15. T. Most, J. Will, Sensitivity analysis using the Metamodel of Optimal Prognosis, in Weimar Optimization and Stochastic Days 8.0, Weimar, (2011) 